\title{
Comment on: Aquatic adaptation in the skull of carnivorous dinosaurs (Theropoda: Spinosauridae) and the evolution of aquatic habits in spinosaurids. 93: 275-284.
}

\author{
HONE David William Elliott ${ }^{1,}{ }^{*}$ HOLTZ Thomas Richard Jnr ${ }^{2,3}$ \\ 1 School of Biological and Chemical Sciences, Queen Mary University of London, London, \\ E1 4NS, UK
}

\section{Department of Geology, University of Maryland, College Park, MD 20742 USA}

3 Department of Paleobiology, National Museum of Natural History, Washington, DC 20560 USA

*Corresponding author: d.hone@qmul.ac.uk

\begin{abstract}
In a recent paper, the contention that spinosaurine theropods were semi-aquatic was supported by Arden et al., (2018) and they provided a hypothetical sequence of acquisition of traits that had evolved in line with this lifestyle. However, we find that the presented traits were either loosely defined and / or are clearly distinct from those traits seen in extant animals with adaptations to life in water. Some spinosaurs may have spent extensive time in water, but the data to support this is currently insufficient and other hypotheses for their behaviour also fit the available data.
\end{abstract}

\section{Background}

Recently Arden et al. (2018) described new spinosaur cranial material and supported the hypothesis that spinosaurine theropods were well adapted to a semi-aquatic lifestyle. However, the evidence is less clear-cut than suggested, and the lack of detail in some comparisons leaves the matter still open to discussion. In particular, the very term 'semiaquatic' is poorly defined in the literature and may refer to almost any terrestrially-capable tetrapod that spends some time in water from pinnipeds to artiodactyls (e.g. Kobus). Ibrahim et al. (2014) point to adaptations in Spinosaurus that are reminiscent of ancestral whales, coupled with an inferred reduced capability on land. Additionally, Arden et al. (2018) suggest large spinosaurs may have replaced large crocodiles, suggesting both these sets of authors regard spinosaurs as more aquatic than terrestrial. Therefore, we refer to 'semi-aquatic' lifestyles here in the sense of an animal with crocodilian-like habits.

Although spinosaurs have long been recognised as animals that likely spent time in and around water to forage (e.g., Taquet, 1984; Paul, 1988; Charig \& Milner, 1997) only recently has it been suggested that some may have been specialised to spend a considerable portion of their lives in water (Ibrahim et al., 2014; Arden et al., 2018). Support for this comes from various lines of evidence, including fish as gut content (Charig \& Milner, 1997), isotopic signatures of the teeth indicating prolonged time spent in water (Amiot et al., 2010), evidence from skull mechanics (Rayfield et al., 2007), retracted nostrils (Sues et al., 2002) and more recently, reduced hindlimbs and pelvic girdle, pachystotic bones and expanded toes (Ibrahim et al., 2014). However, the supporting evidence is not clear cut.

As noted by Hone and Holtz (2017), despite their rarity, spinosaurs show a remarkable diversity of apparent prey compared to other theropods suggesting a broad diet 
and one that likely therefore included foraging outside of the water. Amiot et al. (2010) showed in an analysis of isotopes that a number of specimens had signatures corresponding to animals living in arid conditions and with values closer to non-spinosaur theropods than local crocodilians turtles and fish, and although spinosaurs do have nares that are posteriorly positioned (Hone and Holtz, 2017), they are not dorsally located as would be expected of an animal living in water.

Arden et al. (2018) overlook these potential discrepancies and suggest that the elevated orbits and a crocodile-like bauplan would make spinosaurines well adapted to aquatic life. Spinosaurines do appear to possess somewhat 'raised orbital rims' (Arden et al., 2018) but so too do, for example, such varied dinosaurian taxa as Gallimimus (Osmólska et al., 1972), Skorpiovenator (Canale et al., 2009) Thescelosaurus (Boyd, 2014) Edmontosaurus (Campione \& Evans, 2011), Pentaceratops (Osborne, 1923), and Herrerasaurus (Sereno \& Novas, 1992), (Fig 1) none of which are suggested to have had aquatic affinities. In contrast, the recently described Halszkaraptor (Cau et al., 2017), that has been suggested to have been adapted to an aquatic life, lacks them. Arden et al.'s (2018) figure 6 shows that for a spinosaur submerged in water, the orbits are already held well clear of the surface and the elevated rims makes no difference to in keeping the eyes clear with an oitherwise fully submerged head. Such a posture is required because the nares are not dorsally positioned (Fig 1A-C). Semi-aquatic animals may sit with much of the head above the water, but spinosaurs could not get to a crocodile-like or hippo-like posture with only the nares and eyes exposed, and they lack the highly exaggerated dorsal rims and dorsally directed orbits that these animals show. Arden et al. (2018) state that 'in hippos the bony naris is retracted but not elevated' but the naris in these are also in line with the orbits, which is not the case with spinosaurs (see Fig 1) so the comparison here is not useful.

It is suggested by Arden et al. (2018) that spinosaurs have reduced olfactory bulbs which would support an interpretation of them as aquatic predators as '[o]lfactory cues would have been of little use to an animal that primarily hunted underwater' although this assumes that spinosaurs did predominantly hunt underwater, and at least some animals that hunt underwater have a good olfactory sense (Sorex, Catania, 2006; Pinnipedia, Hanke and Dehnhardt, 2013; Crocodylia and some Testudines, Schwenk, 2008). Arden et al. (2018) cited Corfield et al., (2015) to support their case, but these authors state that 'Living and foraging in a semi-aquatic environment was the strongest variable driving the evolution of large [olfactory bulbs] in birds' while both aquatic and terrestrial birds generally showed smaller bulbs, and there was considerable spread in the data that also varied with factors such as flight. Furthermore, the olfactory bulbs of Alligator mississippiensis are expanded relative to that of most theropod dinosaurs, equalling or exceeding those of tyrannosaurids and dromaeosaurids (Zelenitzky et al., 2008). Although alligators may use this sense to detect carrion, it contradicts the suggestion that olfaction is not of use to animals which hunt underwater. Hence, we have extant aquatic or semi-aquatic archosaurs with reduced olfactory bulbs, as well as expanded ones (or at least a good sense of smell). Thus, the issue of olfactory bulb size in spinosaurids may provide only limited insight one way or the other on their environmental habit with regards to life in the water; it merely indicates they lacked a powerful sense of smell.

\section{Discussion}


Swimming adaptions and an evolutionary pathway to semi-aquatic lifestyles are also discussed by Arden et al. (2018) but these are also problematic. In their figure 4, Arden et al. (2018) state that ' 1 . In early spinosaurids, caudal neural spines are elongated, suggesting use of the tail for swimming; 2. In spinosaurines such as Ichthyovenator, the pelvic elements show reduction of the pubis and ischium, with the pubis being shorter than the ilium, suggesting increased reliance on aquatic versus terrestrial locomotion; 3 , the nostril is retracted in Irritator and Spinosaurus; allowing the animal to breathe while the snout is underwater; 4, frontals are arched in lateral view and the orbits are upturned, putting the eyes out of the water while swimming; 5, elongation of the dorsal vertebrae in Spinosaurini results in a long, crocodile-like body plan for lower drag in the water.' However, we find problems with each of these contentions.

1. Charig and Milner (1997) describe the limited remains of the neural spines of the distal vertebral column of Baryonyx as being a caudal or sacral and are broad, but were not described as being elongated (i.e. tall). The one well preserved neural spine is similar in size to those of the middle and posterior dorsals, so even if it does represent caudal material, in form it is not distinctive compared to more anterior parts of the series. Sereno et al. (1998) similarly illustrate the sacral neural spines of Suchomimus as being taller than those of the tail and contra Arden et al. (2018), this paper does not suggest that the neural spines are an adaptation for swimming. Crocodiles do have tall neural spines in the middle and distal caudals but spinosaurs do not and the neural spines of crocodiles are sub-circular in cross section not flat and blade-like (DWEH pers obs), so this suggested analogy of form is lacking when they are compared in more detail.

2. Arden et al (2018) suggest that a reduced pelvis would support adaptations to swimming, as it points to a reduced reliance on terrestrial locomotion. We agree that the reduced total pelvis size in Spinosaurus is a trait potentially associated with reduced terrestriality. However, the relative proportions of the elements within the pelvis do not seem to have a particular correspondence with aquatic versus terrestrial locomotion. Of note, the pubis is shorter in the ilium in numerous fully terrestrial theropods (e.g., Torvosaurus, Galton and Jensen, 1979; Carnotaurus, Bonaparte et al., 1990; Compsognathus, Ostrom, 1978; Gallimimus, Osmólska et al., 1972; Xixianykus, Xu et al., 2010; and Tyrannosaurus, Brochu, 2003, and in this genus the ischium is also greatly reduced). The size of the ilium in Megalosaurus relative to the femur and the snout-vent length of the animal is near identical to that of Baryonyx, and the ilium is larger than that of some basal theropods (e.g.,

Ceratosaurus, Dilophosaurus - all measured from Hendrickx et al., 2015) suggesting no early reduction and indeed a larger pelvis in early megalosaurs than their ancestors. Thus, there is no clear association of an ilium longer than a pubis or even a reduced ischium is linked directly to a specialisation for swimming in spinosaurs or a reduced terrestrial capability and such a description requires much clearer definition.

3. As noted above, the nares of spinosaurs are laterally positioned, but in Suchomimus the nares apparently sit dorsally relative to the orbit (Sereno et al., 1998, and see Fig 1G here). This then implies these have shifted to a more ventral position in more derived spinosaurs despite the implication of Arden et al. that spinosaurines are better adapted for an aquatic lifestyle than baryonychines. An alternative hypothesis is that the posterior (rather than dorsal) displacement of the external and internal nares in spinosaurids relative to other theropods (and in spinosaurines relative to baryonychines) allowed these dinosaurs to have their anterior snouts positioned in the water waiting for passing fish while their air passage was clear. Such a behaviour would be present in a heron-like posture, but not in an animal which spent the majority of its foraging time submerged. 
4. The position of the orbits was discussed previously. To reiterate, unlike the condition in Hippopotamus or crocodilians, in spinosaurids the orbits are not positioned dorsally enough that they would be emergent when most of the skull is beneath the water line. Instead, much of the posterior of the skull and the anterior portion of the neck would have to be visible in order for the eyes to clear the water level.

5. Crocodiles do not have tall dorsal neural spines or a spinosaur-like cross section to the body (see Henderson, 2018). Most recently Henderson (2018) has also challenged the idea of Spinosaurus being well suited to swimming demonstrating that it would have been unstable in water and prone to rolling, and that despite pachystotic bones, its pneumatic system would have made it difficult for it to dive. Henderson (2018) also showed that spinosaurines would float in a position similar to all other theropods with the head well above water and do not appear to have a body plan that would give them a crocodile or hippo-like posture in water.

Thus we consider this proposed sequence of accumulated traits questionable. There are clear differences between spinosaurs and other theropods, and between baryonychines and spinosaurines, but the lack of near complete skeletons from multiple spinosaurid taxa hampers such comparisons in addition to the issues we raise here. By extension, attempting to reconstruct the ecology and behaviours of such animals is difficult, but it must at least be consistent. Arden et al. (2018) suggest that baryonychines fished like bears or herons (a suggestion that has been made before, e.g. Paul, 1988; Charig \& Milner, 1997) but if this is the case, it does not require that the animals be well adapted for swimming, but would potentially fit with a retracted, but not dorsally positioned naris, which would allow the snout to be in water when foraging (Hone \& Holtz, 2017 - Fig1 B, G). Notably, many herons, storks and other waders also have both raised orbits and retracted nares (DWEH pers obs also Fig 1D).

It was suggested by Arden et al. (2018) that spinosaurs were 'widespread and must have been important members of the freshwater community in the middle Cretaceous' but this is not necessarily true. For example, Hone et al. (2010) previously already noted how rare spinosaur fossils are in most communities in which they have been found, despite factors that should favour their preservation. Therefore, while they may have been widespread they were not necessarily common in most ecosystems nor necessarily important members of a community, and it is perhaps impossible to determine how 'important' something is. Common species could potentially be replaced by others if there is heavy niche overlap without affecting the rest of the ecosystem or major interactions being altered.

\section{Conclusions}

Spinosaurs clearly show some adaptations to a partially or predominantly piscivorous diet and may well have been semi-aquatic animals, but consistent support is required to establish hypotheses of behaviour and ecology in extinct animals. The lack of anatomical data in such incomplete taxa as spinosaurs and the lack of detail in comparisons and analogies leaves the evidence presented as lacking. Interpreting behaviours and ecology in extinct organisms requires clear hypotheses and detailed comparisons and definitions (Hone \& Faulkes, 2014). The general lines of argument presented by Arden et al. may well prove to be important indicators of the behavioural ecology of the spinosaurs but more detailed information is required to assess these effectively. Apparent exceptions and contradictions need to be rationalised to support the contention that spinosaurs (and in particular 
spinosaurines) were specialised semi-aquatic animals spending considerable amount of time in water and were well adapted for swimming. At present it remains difficult to decisively choose between the degree to which the various spinosaurs were primarily aquatic, primarily terrestrial, or some intermediate ecology (Hone \& Holtz, 2017).

\section{Acknowledgements}

We thank Scott Hartman and Eric Snively for useful discussions and comments on an earlier version of the manuscript and Kevin Seymour for access to specimens shown in Figure 1. We thank Yun Chan-Gyu for pointing out that we had previously failed to cite Greg Paul as having noted the relationship between Baryonyx and Spinosaurus.

\section{References}

Alcober, O.A. and Martinez, R.N., 2010. A new herrerasaurid (Dinosauria, Saurischia) from the Upper Triassic Ischigualasto Formation of northwestern Argentina. ZooKeys, 63: 55.

Allain, R., Xaisanavong, T., Richir, P. and Khentavong, B., 2012. The first definitive Asian spinosaurid (Dinosauria: Theropoda) from the early cretaceous of Laos. Naturwissenschaften, 99: 369-377.

Amiot, R., Wang, X., Lécuyer, C., Buffetaut, E., Boudad, L., Cavin, L., Ding, Z., Fluteau, F., Kellner, A.W., Tong, H. and Zhang, F., 2010. Oxygen and carbon isotope compositions of middle Cretaceous vertebrates from North Africa and Brazil: Ecological and environmental significance. Palaeogeography, Palaeoclimatology, Palaeoecology, 297: 439-451.

Arden, T.M., Klein, C.G., Zouhri, S. and Longrich, N.R., 2019. Aquatic adaptation in the skull of carnivorous dinosaurs (Theropoda: Spinosauridae) and the evolution of aquatic habits in spinosaurids. Cretaceous Research, 93: 275-284.

Bonaparte, J.F., Novas, F.E. and Coria, R.A., 1990. Carnotaurus sastrei Bonaparte, the horned, lightly built carnosaur from the Middle Cretaceous of Patagonia.

Boyd, C.A., 2014. The cranial anatomy of the neornithischian dinosaur Thescelosaurus neglectus. PeerJ, 2: p.e669.

Brochu, C.A., 2003. Osteology of Tyrannosaurus rex: insights from a nearly complete skeleton and high-resolution computed tomographic analysis of the skull. Journal of Vertebrate Paleontology, 22(sup4): 1-138.

Campione, N.E. and Evans, D.C., 2011. Cranial growth and variation in edmontosaurs (Dinosauria: Hadrosauridae): implications for latest Cretaceous megaherbivore diversity in North America. PLoS One, 6: p.e25186.

Canale, J.I., Scanferla, C.A., Agnolin, F.L. and Novas, F.E., 2009. New carnivorous dinosaur from the Late Cretaceous of NW Patagonia and the evolution of abelisaurid theropods. Naturwissenschaften, 96:409.

Catania, K.C., 2006. Olfaction: underwater'sniffing'by semi-aquatic mammals. Nature, 44:1024.

Cau, A., Beyrand, V., Voeten, D.F., Fernandez, V., Tafforeau, P., Stein, K., Barsbold, R., Tsogtbaatar, K., Currie, P.J. and Godefroit, P., 2017. Synchrotron scanning reveals 
amphibious ecomorphology in a new clade of bird-like dinosaurs. Nature, 552(7685), p.395.

Charig, A.J., and Milner, A.C., 1997. Baryonyx walkeri, a fish-eating dinosaur from the Wealden of Surrey. Bulletin of the Natural History Museum Geology, 53: 11-70.

Corfield, J.R., Price, K., Iwaniuk, A.N., Gutiérrez-Ibáñez, C., Birkhead, T. and Wylie, D.R., 2015. Diversity in olfactory bulb size in birds reflects allometry, ecology, and phylogeny. Frontiers in neuroanatomy, 9: 102.

Galton, P.M. and Jensen, J.A., 1979. A new large theropod dinosaur from the Upper Jurassic of Colorado. Brigham Young University Geology Studies, 26: 1-12.

Hanke, W. and Dehnhardt, G., 2013. Sensory biology of aquatic mammals. Springer.

Hendrickx, C., Hartman, S.A. and Mateus, O., 2015. An overview of non-avian theropod discoveries and classification. PalArch's Journal of Vertebrate Palaeontology, 12: 1.

Henderson, D.M., 2018. A buoyancy, balance and stability challenge to the hypothesis of a semi-aquatic Spinosaurus Stromer, 1915 (Dinosauria: Theropoda). PeerJ, 6: p.e5409.

Hone, D.W.E., Xu, X. and Wang, D.Y., 2010. A probable baryonychine (Theropoda: Spinosauridae) tooth from the Upper Cretaceous of Henan Province, China. Vertebrata PalAsiatica, 48: 19-26.

Hone, D.W.E., and Faulkes, C.J., 2014. A proposed framework for establishing and evaluating hypotheses about the behaviour of extinct organisms. Journal of Zoology, 292: 260-267.

Hone, D.W.E. and Holtz Jr, T.R., 2017. A century of spinosaurs-a review and revision of the Spinosauridae with comments on their ecology. Acta Geologica Sinica-English Edition, 93: 1120-1132.

Ibrahim, N., Sereno, P.C., Dal Sasso, C., Maganuco, S., Fabbri, M., Martill, D.M., Zouhri, S., Myhrvold, N., Iurino, D.A., 2014. Semiaquatic adaptations in a giant predatory dinosaur. Science, 345: 1613-1616.

Osborn, H.F. 1923, "A new genus and species of Ceratopsia from New Mexico, Pentaceratops sternbergii, American Museum Novitates, 93: 1-3

Osmólska, H., Roniewicz, E. and Barsbold, R., 1972. A new dinosaur, Gallimimus bullatus n. gen., n. sp.(Ornithomimidae) from the Upper Cretaceous of Mongolia.

Ostrom, J.H., 1978. The osteology of Compsognathus longipes Wagner. Zitteliana.

Paul, G.S. 1988. Predatory Dinosaurs of the World: A Complete Illustrated Guide. Simon and Schuster, New York. 464 pp.

Rayfield, E., Milner, A.C., Xuan, V.B., and Young, P.G., 2007. Functional morphology of spinosaur 'crocodile mimic' dinosaurs. Journal of Vertebrate Paleontology, 27: 892901.

Schwenk, K. 2008. Comparative anatomy and physiology of chemical senses in nonavian aquatic reptiles. Sensory Evolution on the Thresholds: Adaptations in Secondarily Aquatic Vertebrates. University of California Press, Berkeley, California, pp.65-81.

Sereno, P.C., and Novas, F.E., 1992. The complete skull and skeleton of an early dinosaur. Science, 258: 1137-1140.

Sereno, P.C., Beck, A.L., Dutheil, D.B., Gado, B., Larsson, H.C.E., Lyon, G.H., Marcot, J.D., Rauhut, O.W.M., Sadleir, R.W, Sidor, C.A., Varricchio, D.D., Wilson, G.P., and Wilson, J.A. 1998. A long-snouted predatory dinosaur from Africa and the evolution of Spinosaurids. Science, 282: 1298-1302. 
Sues, H.-D., Frey, E., Martill, D.M., and Scott, D.M., 2002. Irritator challengeri, a spinosaurid (Dinosauria: Theropoda) from the Lower Cretaceous of Brazil. Journal of Vertebrate Paleontology, 22: 535-547.

Taquet, P., 1984. Une curieuse spécialisation du crâne de certains Dinosaures carnivores du Crétacé: le museau long et étroit des Spinosauridés. Comptes Rendus de l'Academie des Sciences, Série II, 299: 217-222.

Tykoski, R.S., 2005. Anatomy, ontogeny and phylogeny of coelophysoid theropods. Thesis, University of Texas, Austin, 553pp.

Xu, X., Wang, D.Y., Sullivan, C., Hone, D.W., Han, F.L., Yan, R.H. and Du, F.M., 2010. A basal parvicursorine (Theropoda: Alvarezsauridae) from the Upper Cretaceous of China. Zootaxa, 2413: 1-19.

Zelenitsky, D.K., Therrien, F. and Kobayashi, Y., 2008. Olfactory acuity in theropods: palaeobiological and evolutionary implications. Proceedings of the Royal Society B: Biological Sciences, 276: 667-673.

Figure 1. A. Caiman crocodilius floating in water in which little more than the nostrils and eyes are exposed and the snout is underwater, contrasting with B. the skull of a spinosaurine (redrawn from Arden et al., 2018) which shows much of the head above the water because of the position of the nares. C. Hippopotamus amphibius shows aquatic adaptations with dorsally raised orbits but a lesser degree of this close to the spinosaur condition is also seen in modern dinosaurs such as D. Ardea herodias and Mesozoic ones such as E. Gallimimus bullatus (redrawn from Osmólska et al., 1972), F. Coelophysis bauri (redrawn from Tykoski, 2005) but this is not seen in G. the skull of Suchomimus tenerensis (redrawn from Sereno et al., 1998). 


\title{
Comment on: Aquatic adaptation in the skull of carnivorous dinosaurs (Theropoda: Spinosauridae) and the evolution of aquatic habits in spinosaurids. 93: 275-284.
}

\author{
HONE David William Elliott ${ }^{1,}{ }^{*}$ HOLTZ Thomas Richard Jnr ${ }^{2,3}$ \\ 1 School of Biological and Chemical Sciences, Queen Mary University of London, London, \\ E1 4NS, UK
}

\section{Department of Geology, University of Maryland, College Park, MD 20742 USA}

\section{Department of Paleobiology, National Museum of Natural History, Washington, DC 20560 USA}

*Corresponding author: d.hone@qmul.ac.uk

\begin{abstract}
In a recent paper, the contention that spinosaurine theropods were semi-aquatic was supported by Arden et al., (2018) and they provided a hypothetical sequence of acquisition of traits that had evolved in line with this lifestyle. However, we find that the presented traits were either loosely defined and / or are clearly distinct from those traits seen in extant animals with adaptations to life in water. Some spinosaurs may have spent extensive time in water, but the data to support this is currently insufficient and other hypotheses for their behaviour also fit the available data.
\end{abstract}

\section{Background}

Recently Arden et al. (2018) described new spinosaur cranial material and supported the hypothesis that spinosaurine theropods were well adapted to a semi-aquatic lifestyle. However, the evidence is less clear-cut than suggested, and the lack of detail in some comparisons leaves the matter still open to discussion. In particular, the very term 'semiaquatic' is poorly defined in the literature and may refer to almost any terrestrially-capable tetrapod that spends some time in water from pinnipeds to artiodactyls (e.g. Kobus). Ibrahim et al. (2014) point to adaptations in Spinosaurus that are reminiscent of ancestral whales, coupled with an inferred reduced capability on land. Additionally, Arden et al. (2018) suggest large spinosaurs may have replaced large crocodiles, suggesting both these sets of authors regard spinosaurs as more aquatic than terrestrial. Therefore, we refer to 'semi-aquatic' lifestyles here in the sense of an animal with crocodilian-like habits.

Although spinosaurs have long been recognised as animals that likely spent time in and around water to forage (e.g., Taquet, 1984; Paul, 1988; Charig \& Milner, 1997) only recently has it been suggested that some may have been specialised to spend a considerable portion of their lives in water (Ibrahim et al., 2014; Arden et al., 2018). Support for this comes from various lines of evidence, including fish as gut content (Charig \& Milner, 1997), isotopic signatures of the teeth indicating prolonged time spent in water (Amiot et al., 2010), evidence from skull mechanics (Rayfield et al., 2007), retracted nostrils (Sues et al., 2002) and more recently, reduced hindlimbs and pelvic girdle, pachystotic bones and expanded toes (Ibrahim et al., 2014). However, the supporting evidence is not clear cut.

As noted by Hone and Holtz (2017), despite their rarity, spinosaurs show a remarkable diversity of apparent prey compared to other theropods suggesting a broad diet 
and one that likely therefore included foraging outside of the water. Amiot et al. (2010) showed in an analysis of isotopes that a number of specimens had signatures corresponding to animals living in arid conditions and with values closer to non-spinosaur theropods than local crocodilians turtles and fish, and although spinosaurs do have nares that are posteriorly positioned (Hone and Holtz, 2017), they are not dorsally located as would be expected of an animal living in water.

Arden et al. (2018) overlook these potential discrepancies and suggest that the elevated orbits and a crocodile-like bauplan would make spinosaurines well adapted to aquatic life. Spinosaurines do appear to possess somewhat 'raised orbital rims' (Arden et al., 2018) but so too do, for example, such varied dinosaurian taxa as Gallimimus (Osmólska et al., 1972), Skorpiovenator (Canale et al., 2009) Thescelosaurus (Boyd, 2014) Edmontosaurus (Campione \& Evans, 2011), Pentaceratops (Osborne, 1923), and Herrerasaurus (Sereno \& Novas, 1992), (Fig 1) none of which are suggested to have had aquatic affinities. In contrast, the recently described Halszkaraptor (Cau et al., 2017), that has been suggested to have been adapted to an aquatic life, lacks them. Arden et al.'s (2018) figure 6 shows that for a spinosaur submerged in water, the orbits are already held well clear of the surface and the elevated rims makes no difference to in keeping the eyes clear with an oitherwise fully submerged head. Such a posture is required because the nares are not dorsally positioned (Fig 1A-C). Semi-aquatic animals may sit with much of the head above the water, but spinosaurs could not get to a crocodile-like or hippo-like posture with only the nares and eyes exposed, and they lack the highly exaggerated dorsal rims and dorsally directed orbits that these animals show. Arden et al. (2018) state that 'in hippos the bony naris is retracted but not elevated' but the naris in these are also in line with the orbits, which is not the case with spinosaurs (see Fig 1) so the comparison here is not useful.

It is suggested by Arden et al. (2018) that spinosaurs have reduced olfactory bulbs which would support an interpretation of them as aquatic predators as '[o]lfactory cues would have been of little use to an animal that primarily hunted underwater' although this assumes that spinosaurs did predominantly hunt underwater, and at least some animals that hunt underwater have a good olfactory sense (Sorex, Catania, 2006; Pinnipedia, Hanke and Dehnhardt, 2013; Crocodylia and some Testudines, Schwenk, 2008). Arden et al. (2018) cited Corfield et al., (2015) to support their case, but these authors state that 'Living and foraging in a semi-aquatic environment was the strongest variable driving the evolution of large [olfactory bulbs] in birds' while both aquatic and terrestrial birds generally showed smaller bulbs, and there was considerable spread in the data that also varied with factors such as flight. Furthermore, the olfactory bulbs of Alligator mississippiensis are expanded relative to that of most theropod dinosaurs, equalling or exceeding those of tyrannosaurids and dromaeosaurids (Zelenitzky et al., 2008). Although alligators may use this sense to detect carrion, it contradicts the suggestion that olfaction is not of use to animals which hunt underwater. Hence, we have extant aquatic or semi-aquatic archosaurs with reduced olfactory bulbs, as well as expanded ones (or at least a good sense of smell). Thus, the issue of olfactory bulb size in spinosaurids may provide only limited insight one way or the other on their environmental habit with regards to life in the water; it merely indicates they lacked a powerful sense of smell.

\section{Discussion}


Swimming adaptions and an evolutionary pathway to semi-aquatic lifestyles are also discussed by Arden et al. (2018) but these are also problematic. In their figure 4, Arden et al. (2018) state that ' 1 . In early spinosaurids, caudal neural spines are elongated, suggesting use of the tail for swimming; 2. In spinosaurines such as Ichthyovenator, the pelvic elements show reduction of the pubis and ischium, with the pubis being shorter than the ilium, suggesting increased reliance on aquatic versus terrestrial locomotion; 3 , the nostril is retracted in Irritator and Spinosaurus; allowing the animal to breathe while the snout is underwater; 4, frontals are arched in lateral view and the orbits are upturned, putting the eyes out of the water while swimming; 5, elongation of the dorsal vertebrae in Spinosaurini results in a long, crocodile-like body plan for lower drag in the water.' However, we find problems with each of these contentions.

1. Charig and Milner (1997) describe the limited remains of the neural spines of the distal vertebral column of Baryonyx as being a caudal or sacral and are broad, but were not described as being elongated (i.e. tall). The one well preserved neural spine is similar in size to those of the middle and posterior dorsals, so even if it does represent caudal material, in form it is not distinctive compared to more anterior parts of the series. Sereno et al. (1998) similarly illustrate the sacral neural spines of Suchomimus as being taller than those of the tail and contra Arden et al. (2018), this paper does not suggest that the neural spines are an adaptation for swimming. Crocodiles do have tall neural spines in the middle and distal caudals but spinosaurs do not and the neural spines of crocodiles are sub-circular in cross section not flat and blade-like (DWEH pers obs), so this suggested analogy of form is lacking when they are compared in more detail.

2. Arden et al (2018) suggest that a reduced pelvis would support adaptations to swimming, as it points to a reduced reliance on terrestrial locomotion. We agree that the reduced total pelvis size in Spinosaurus is a trait potentially associated with reduced terrestriality. However, the relative proportions of the elements within the pelvis do not seem to have a particular correspondence with aquatic versus terrestrial locomotion. Of note, the pubis is shorter in the ilium in numerous fully terrestrial theropods (e.g., Torvosaurus, Galton and Jensen, 1979; Carnotaurus, Bonaparte et al., 1990; Compsognathus, Ostrom, 1978; Gallimimus, Osmólska et al., 1972; Xixianykus, Xu et al., 2010; and Tyrannosaurus, Brochu, 2003, and in this genus the ischium is also greatly reduced). The size of the ilium in Megalosaurus relative to the femur and the snout-vent length of the animal is near identical to that of Baryonyx, and the ilium is larger than that of some basal theropods (e.g.,

Ceratosaurus, Dilophosaurus - all measured from Hendrickx et al., 2015) suggesting no early reduction and indeed a larger pelvis in early megalosaurs than their ancestors. Thus, there is no clear association of an ilium longer than a pubis or even a reduced ischium is linked directly to a specialisation for swimming in spinosaurs or a reduced terrestrial capability and such a description requires much clearer definition.

3. As noted above, the nares of spinosaurs are laterally positioned, but in Suchomimus the nares apparently sit dorsally relative to the orbit (Sereno et al., 1998, and see Fig 1G here). This then implies these have shifted to a more ventral position in more derived spinosaurs despite the implication of Arden et al. that spinosaurines are better adapted for an aquatic lifestyle than baryonychines. An alternative hypothesis is that the posterior (rather than dorsal) displacement of the external and internal nares in spinosaurids relative to other theropods (and in spinosaurines relative to baryonychines) allowed these dinosaurs to have their anterior snouts positioned in the water waiting for passing fish while their air passage was clear. Such a behaviour would be present in a heron-like posture, but not in an animal which spent the majority of its foraging time submerged. 
4. The position of the orbits was discussed previously. To reiterate, unlike the condition in Hippopotamus or crocodilians, in spinosaurids the orbits are not positioned dorsally enough that they would be emergent when most of the skull is beneath the water line. Instead, much of the posterior of the skull and the anterior portion of the neck would have to be visible in order for the eyes to clear the water level.

5. Crocodiles do not have tall dorsal neural spines or a spinosaur-like cross section to the body (see Henderson, 2018). Most recently Henderson (2018) has also challenged the idea of Spinosaurus being well suited to swimming demonstrating that it would have been unstable in water and prone to rolling, and that despite pachystotic bones, its pneumatic system would have made it difficult for it to dive. Henderson (2018) also showed that spinosaurines would float in a position similar to all other theropods with the head well above water and do not appear to have a body plan that would give them a crocodile or hippo-like posture in water.

Thus we consider this proposed sequence of accumulated traits questionable. There are clear differences between spinosaurs and other theropods, and between baryonychines and spinosaurines, but the lack of near complete skeletons from multiple spinosaurid taxa hampers such comparisons in addition to the issues we raise here. By extension, attempting to reconstruct the ecology and behaviours of such animals is difficult, but it must at least be consistent. Arden et al. (2018) suggest that baryonychines fished like bears or herons (a suggestion that has been made before, e.g. Paul, 1988; Charig \& Milner, 1997) but if this is the case, it does not require that the animals be well adapted for swimming, but would potentially fit with a retracted, but not dorsally positioned naris, which would allow the snout to be in water when foraging (Hone \& Holtz, 2017 - Fig1 B, G). Notably, many herons, storks and other waders also have both raised orbits and retracted nares (DWEH pers obs also Fig 1D).

It was suggested by Arden et al. (2018) that spinosaurs were 'widespread and must have been important members of the freshwater community in the middle Cretaceous' but this is not necessarily true. For example, Hone et al. (2010) previously already noted how rare spinosaur fossils are in most communities in which they have been found, despite factors that should favour their preservation. Therefore, while they may have been widespread they were not necessarily common in most ecosystems nor necessarily important members of a community, and it is perhaps impossible to determine how 'important' something is. Common species could potentially be replaced by others if there is heavy niche overlap without affecting the rest of the ecosystem or major interactions being altered.

\section{Conclusions}

Spinosaurs clearly show some adaptations to a partially or predominantly piscivorous diet and may well have been semi-aquatic animals, but consistent support is required to establish hypotheses of behaviour and ecology in extinct animals. The lack of anatomical data in such incomplete taxa as spinosaurs and the lack of detail in comparisons and analogies leaves the evidence presented as lacking. Interpreting behaviours and ecology in extinct organisms requires clear hypotheses and detailed comparisons and definitions (Hone \& Faulkes, 2014). The general lines of argument presented by Arden et al. may well prove to be important indicators of the behavioural ecology of the spinosaurs but more detailed information is required to assess these effectively. Apparent exceptions and contradictions need to be rationalised to support the contention that spinosaurs (and in particular 
spinosaurines) were specialised semi-aquatic animals spending considerable amount of time in water and were well adapted for swimming. At present it remains difficult to decisively choose between the degree to which the various spinosaurs were primarily aquatic, primarily terrestrial, or some intermediate ecology (Hone \& Holtz, 2017).

\section{Acknowledgements}

We thank Scott Hartman and Eric Snively for useful discussions and comments on an earlier version of the manuscript and Kevin Seymour for access to specimens shown in Figure 1. We thank Yun Chan-Gyu for pointing out that we had previously failed to cite Greg Paul as having noted the relationship between Baryonyx and Spinosaurus.

\section{References}

Alcober, O.A. and Martinez, R.N., 2010. A new herrerasaurid (Dinosauria, Saurischia) from the Upper Triassic Ischigualasto Formation of northwestern Argentina. ZooKeys, 63: 55.

Allain, R., Xaisanavong, T., Richir, P. and Khentavong, B., 2012. The first definitive Asian spinosaurid (Dinosauria: Theropoda) from the early cretaceous of Laos. Naturwissenschaften, 99: 369-377.

Amiot, R., Wang, X., Lécuyer, C., Buffetaut, E., Boudad, L., Cavin, L., Ding, Z., Fluteau, F., Kellner, A.W., Tong, H. and Zhang, F., 2010. Oxygen and carbon isotope compositions of middle Cretaceous vertebrates from North Africa and Brazil: Ecological and environmental significance. Palaeogeography, Palaeoclimatology, Palaeoecology, 297: 439-451.

Arden, T.M., Klein, C.G., Zouhri, S. and Longrich, N.R., 2019. Aquatic adaptation in the skull of carnivorous dinosaurs (Theropoda: Spinosauridae) and the evolution of aquatic habits in spinosaurids. Cretaceous Research, 93: 275-284.

Bonaparte, J.F., Novas, F.E. and Coria, R.A., 1990. Carnotaurus sastrei Bonaparte, the horned, lightly built carnosaur from the Middle Cretaceous of Patagonia.

Boyd, C.A., 2014. The cranial anatomy of the neornithischian dinosaur Thescelosaurus neglectus. PeerJ, 2: p.e669.

Brochu, C.A., 2003. Osteology of Tyrannosaurus rex: insights from a nearly complete skeleton and high-resolution computed tomographic analysis of the skull. Journal of Vertebrate Paleontology, 22(sup4): 1-138.

Campione, N.E. and Evans, D.C., 2011. Cranial growth and variation in edmontosaurs (Dinosauria: Hadrosauridae): implications for latest Cretaceous megaherbivore diversity in North America. PLoS One, 6: p.e25186.

Canale, J.I., Scanferla, C.A., Agnolin, F.L. and Novas, F.E., 2009. New carnivorous dinosaur from the Late Cretaceous of NW Patagonia and the evolution of abelisaurid theropods. Naturwissenschaften, 96:409.

Catania, K.C., 2006. Olfaction: underwater'sniffing'by semi-aquatic mammals. Nature, 44:1024.

Cau, A., Beyrand, V., Voeten, D.F., Fernandez, V., Tafforeau, P., Stein, K., Barsbold, R., Tsogtbaatar, K., Currie, P.J. and Godefroit, P., 2017. Synchrotron scanning reveals 
amphibious ecomorphology in a new clade of bird-like dinosaurs. Nature, 552(7685), p.395.

Charig, A.J., and Milner, A.C., 1997. Baryonyx walkeri, a fish-eating dinosaur from the Wealden of Surrey. Bulletin of the Natural History Museum Geology, 53: 11-70.

Corfield, J.R., Price, K., Iwaniuk, A.N., Gutiérrez-Ibáñez, C., Birkhead, T. and Wylie, D.R., 2015. Diversity in olfactory bulb size in birds reflects allometry, ecology, and phylogeny. Frontiers in neuroanatomy, 9: 102.

Galton, P.M. and Jensen, J.A., 1979. A new large theropod dinosaur from the Upper Jurassic of Colorado. Brigham Young University Geology Studies, 26: 1-12.

Hanke, W. and Dehnhardt, G., 2013. Sensory biology of aquatic mammals. Springer.

Hendrickx, C., Hartman, S.A. and Mateus, O., 2015. An overview of non-avian theropod discoveries and classification. PalArch's Journal of Vertebrate Palaeontology, 12: 1.

Henderson, D.M., 2018. A buoyancy, balance and stability challenge to the hypothesis of a semi-aquatic Spinosaurus Stromer, 1915 (Dinosauria: Theropoda). PeerJ, 6: p.e5409.

Hone, D.W.E., Xu, X. and Wang, D.Y., 2010. A probable baryonychine (Theropoda: Spinosauridae) tooth from the Upper Cretaceous of Henan Province, China. Vertebrata PalAsiatica, 48: 19-26.

Hone, D.W.E., and Faulkes, C.J., 2014. A proposed framework for establishing and evaluating hypotheses about the behaviour of extinct organisms. Journal of Zoology, 292: 260-267.

Hone, D.W.E. and Holtz Jr, T.R., 2017. A century of spinosaurs-a review and revision of the Spinosauridae with comments on their ecology. Acta Geologica Sinica-English Edition, 93: 1120-1132.

Ibrahim, N., Sereno, P.C., Dal Sasso, C., Maganuco, S., Fabbri, M., Martill, D.M., Zouhri, S., Myhrvold, N., Iurino, D.A., 2014. Semiaquatic adaptations in a giant predatory dinosaur. Science, 345: 1613-1616.

Osborn, H.F. 1923, "A new genus and species of Ceratopsia from New Mexico, Pentaceratops sternbergii, American Museum Novitates, 93: 1-3

Osmólska, H., Roniewicz, E. and Barsbold, R., 1972. A new dinosaur, Gallimimus bullatus n. gen., n. sp.(Ornithomimidae) from the Upper Cretaceous of Mongolia.

Ostrom, J.H., 1978. The osteology of Compsognathus longipes Wagner. Zitteliana.

Paul, G.S. 1988. Predatory Dinosaurs of the World: A Complete Illustrated Guide. Simon and Schuster, New York. 464 pp.

Rayfield, E., Milner, A.C., Xuan, V.B., and Young, P.G., 2007. Functional morphology of spinosaur 'crocodile mimic' dinosaurs. Journal of Vertebrate Paleontology, 27: 892901.

Schwenk, K. 2008. Comparative anatomy and physiology of chemical senses in nonavian aquatic reptiles. Sensory Evolution on the Thresholds: Adaptations in Secondarily Aquatic Vertebrates. University of California Press, Berkeley, California, pp.65-81.

Sereno, P.C., and Novas, F.E., 1992. The complete skull and skeleton of an early dinosaur. Science, 258: 1137-1140.

Sereno, P.C., Beck, A.L., Dutheil, D.B., Gado, B., Larsson, H.C.E., Lyon, G.H., Marcot, J.D., Rauhut, O.W.M., Sadleir, R.W, Sidor, C.A., Varricchio, D.D., Wilson, G.P., and Wilson, J.A. 1998. A long-snouted predatory dinosaur from Africa and the evolution of Spinosaurids. Science, 282: 1298-1302. 
Sues, H.-D., Frey, E., Martill, D.M., and Scott, D.M., 2002. Irritator challengeri, a spinosaurid (Dinosauria: Theropoda) from the Lower Cretaceous of Brazil. Journal of Vertebrate Paleontology, 22: 535-547.

Taquet, P., 1984. Une curieuse spécialisation du crâne de certains Dinosaures carnivores du Crétacé: le museau long et étroit des Spinosauridés. Comptes Rendus de l'Academie des Sciences, Série II, 299: 217-222.

Tykoski, R.S., 2005. Anatomy, ontogeny and phylogeny of coelophysoid theropods. Thesis, University of Texas, Austin, 553pp.

Xu, X., Wang, D.Y., Sullivan, C., Hone, D.W., Han, F.L., Yan, R.H. and Du, F.M., 2010. A basal parvicursorine (Theropoda: Alvarezsauridae) from the Upper Cretaceous of China. Zootaxa, 2413: 1-19.

Zelenitsky, D.K., Therrien, F. and Kobayashi, Y., 2008. Olfactory acuity in theropods: palaeobiological and evolutionary implications. Proceedings of the Royal Society B: Biological Sciences, 276: 667-673. 

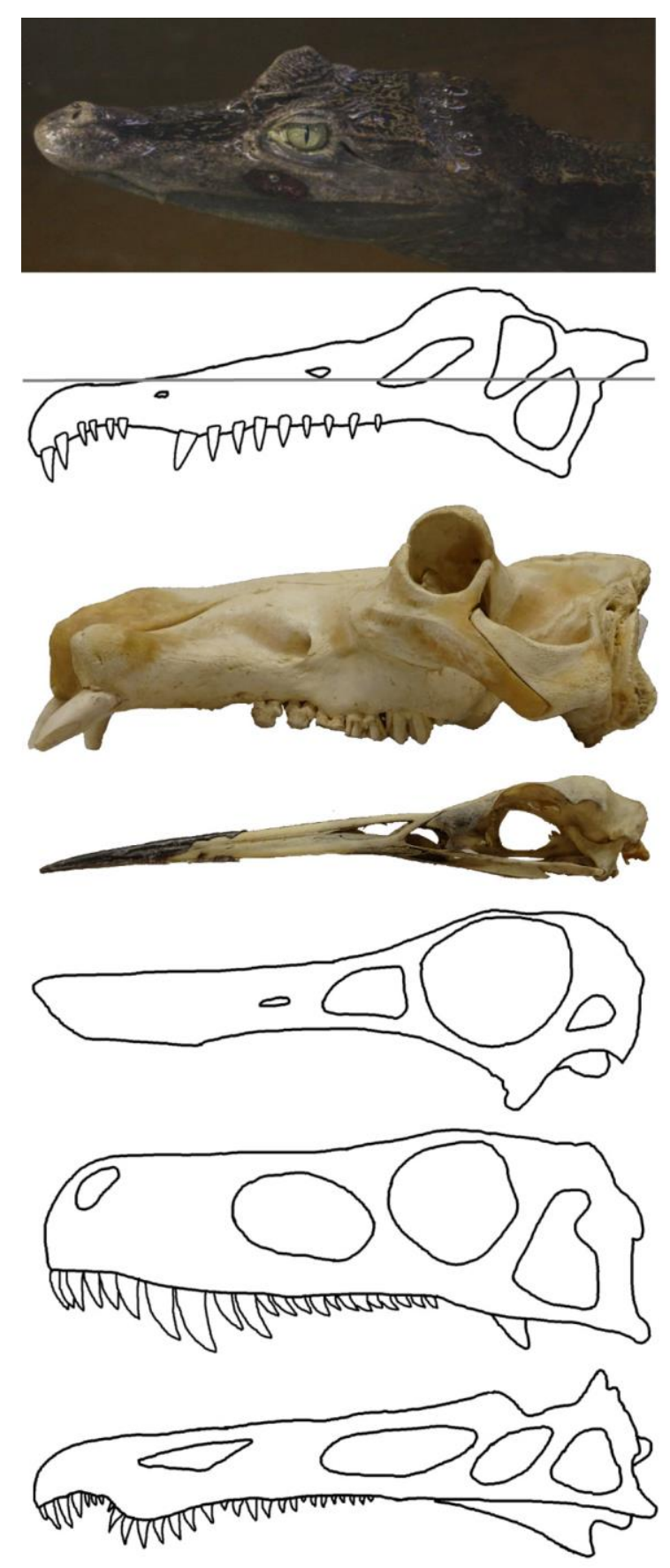

Figure 1. A. Caiman crocodilius floating in water in which little more than the nostrils and eyes are exposed and the snout is underwater, contrasting with B. the skull of a spinosaurine (redrawn from Arden et al., 2018) which shows much of the head above the water because of the position of the nares. C. Hippopotamus amphibius shows aquatic adaptations with dorsally raised orbits but a lesser degree of this close to the spinosaur condition is also seen in modern dinosaurs such as D. Ardea herodias and Mesozoic ones such as E. Gallimimus bullatus (redrawn from Osmólska et al., 1972), F. Coelophysis bauri (redrawn from Tykoski, 2005) but this is not seen in G. the skull of Suchomimus tenerensis (redrawn from Sereno et al., 1998). 